\section{Primary Care Informatics Response to Covid-19 Pandemic: Adaptation, Progress, and Lessons from Four Countries with High ICT Development}

\author{
Siaw-Teng Liaw', Craig Kuziemsky², Richard Schreiber ${ }^{3}$, Jitendra Jonnagaddala', Harshana \\ Liyanage ${ }^{4}$, Aliasgar Chittalia ${ }^{5}$, Ravninder Bahniwal ${ }^{6}$, Jennifer W. He ${ }^{7}$, Bridget L. Ryan ${ }^{8}$, \\ Daniel J. Lizotte ${ }^{9}$, Jacqueline K. Kueper ${ }^{7}$, Amanda L. Terry ${ }^{8}$, Simon de Lusignan ${ }^{4}$ \\ 1 WHO Collaborating Centre on eHealth, UNSW Sydney, Australia \\ 2 MacEwan University, Edmonton, Alberta, Canada \\ 3 Penn State Health Holy Spirit Medical Center, Camp Hill, Pennsylvania, USA \\ 4 Nuffield Department of Primary Care Health Sciences, University of Oxford, UK \\ 5 Family Practice Center, Mountaintop, Pennsylvania, USA \\ 6 Schulich Interfaculty Program in Public Health, Western University, London, Canada \\ 7 Graduate Program in Epidemiology and Biostatistics, Western University, London, Canada \\ ${ }^{8}$ Centre for Studies in Family Medicine, Department of Family Medicine, Western University, \\ London, Canada \\ 9 Department of Computer Science, Western University, London, Canada
}

\section{Summary}

Objective: Internationally, primary care practice had to transform in response to the COVID pandemic. Informatics issues included access, privacy, and security, as well as patient concerns of equity, safety, quality, and trust. This paper describes progress and lessons learned.

Methods: IMIA Primary Care Informatics Working Group members from Australia, Canada, United Kingdom and United States developed a standardised template for collection of information. The template guided a rapid literature review. We also included experiential learning from primary care and public health perspectives.
Results: All countries responded rapidly. Common themes included rapid reductions then transformation to virtual visits, pausing of non-COVID related informatics projects, all against a background of non-standardized digital development and disparate territory or state regulations and guidance. Common barriers in these four and in less-resourced countries included disparities in internet access and availability including bandwidth limitations when internet access was available, initial lack of coding standards, and fears of primary care clinicians that patients were delaying care despite the availability of televisits. Conclusions: Primary care clinicians were able to respond to the COVID crisis through telehealth and electronic record enabled change. However, the lack of coordinated national strategies and regulation, assurance of financial viability, and working in silos remained limitations. The potential for primary care informatics to transform current practice was highlighted. More research is needed to confirm preliminary observations and trends noted.

\section{Keywords}

Telemedicine, Primary Health Care, health policy, public health, severe acute respiratory syndrome coronavirus 2

Yearb Med Inform 2021:44-55 http://dx.doi.org/10.1055/s-0041-1726489

\section{Introduction}

Primary care informatics (PCI) is the science that underpins digital health in the community, empowering patients, carers, citizens, health professionals and health organisations in the delivery of safe, effective, and integrated patient-centred care.

Global progress towards digital health maturity [1] was slow until the COVID-19 pandemic when information and commu- nication technology (ICT) developments and telehealth were "fast-forwarded" to support the rapid and ongoing response to the COVID-19 pandemic [2].

Primary care had to deal with managing personal protective equipment (PPE), public health guidelines such as hand hygiene and social distancing, and contact tracing apps, and informatics issues including technical issues (network connectivity \& user interfaces), limited physical examination, privacy and ethical issues, participants' literacy, cost, reimbursement, and regulatory barriers [3]. Despite a lack of evidence for the access, equity, utility, safety and quality of telehealth, it quickly became policy (Box 1) [4]. The scope to develop PCI and digital health to support primary care during COVID-19 cannot be separated from policy, human resources and other system limitations $[5,6]$. 


\begin{tabular}{|} 
"Our government's response to the \\
pandemic brought forward a 10-year \\
plan on telehealth within 10 days." \\
Australian Health Minister \\
"These investments will help provide \\
Canadians with virtual health care \\
services that are safe and secure." \\
Canadian Federal Minster or Health \\
"GP tele-consultations should be \\
default unless reason not to." \\
United Kingdom Health Secretary \\
"Please don't give up. Don't despair, \\
the end is in sight,' as opposed to: \\
'Hey, we are good to go, don't worry \\
about anything.' We are not good \\
to go. We have got to continue to \\
double down on public health mea- \\
sures." \\
Dr. Anthony Fauci, COVID advisor \\
to the President of the United States \\
of America
\end{tabular}

Box 1 Quotes from health system leaders about the shift towards digital health

\section{Objectives}

We examine the use of PCI and telehealth across the COVID-19 pandemic across countries with variable resources and levels of digital health maturity. We report how PCI supported the transformation of health systems focusing on virtual primary care encounters, documenting areas of accelerated progress and lessons learned.

\section{Methods}

Volunteer members of the IMIA Primary Care Informatics Working Group developed a template to standardise the collection of relevant PCI concepts and information. We described the primary care system in each country, then how PCI was used and adapted, extent of success, and lessons learnt from each country. We present data from four countries (Australia, Canada, USA, UK) ranked in the top 30 of 176 countries with an International Telecommunication Union ICT Development Index [7] and provided an international comparison with data from India (ranked 134) and Pacific Islands (Kiribati ranked 154).

The concepts guided the limited scoping literature review for each of the countries. Search terms included: primary health care, family medicine, general practice, population, health, medical, informatics, telemedicine, telehealth, teleconsultation, virtual, consultation, encounter, videoconference, COVID-19, equity, disparities, health insurance, health benefits, accessibility, privacy, computer security, regulatory, regulations, risk, and various short forms with wildcards.

We enhanced the literature review with personal experiences with COVID-19 from the primary care and public health perspectives in our respective countries. We also examined issues with data custodianship and stewardship of primary care data repositories in the UK and Australia. We then summarised and synthesised the information to identify the impacts of COVID-19 on primary care, how PCI adapted, and how it may evolve into the future and a new normal for primary care.

\section{Results: $\mathrm{PCl}$ response to COVID-19}

\subsection{Australia}

\section{a Healthcare system}

The Australian federated health system is complex and fragmented, but evolving towards an integrated, citizen-centred, accountable and sustainable system. The My Health Record system addressed information sharing and integrated care delivery. There was little progress on foundational elements such as e-prescribing and computerised physician order entry (CPOE) in primary care. Whilst the Australian Medicare Benefits Schedule (MBS) has included specialist telehealth items since 2011 there were no general practice (GP) items, apparently because of risks of fraud/ over-servicing [8].
However, the Australian National COVID-19 Primary Care Response changed this and implemented expanded access to telehealth services, training of the health workforce, 24-hour health advice, dedicated community-based "respiratory" clinics, and enhanced protection for remote communities [9].

\section{b COVID-19 Impacts on Primary Care Delivery in Australia}

Temporary telehealth items introduced in March 2020 for 6 months significantly accelerated a shift from physical "in-person" consultations to virtual face-to-face consultations [10]. Telemedicine activities peaked in April, 2020 at $38 \%$ of all ambulatory visits captured in the Australian Medicare program [11]. In the first 40 weeks of COVID-19, a significant initial increase in phone consultations was maintained but the small initial increase in video consultations was not (Figure 1) [12]. Telehealth has enabled $85 \%$ patients with COVID-19 to be managed in the community, including patients suspected of SARS-CoV-2 (Severe Acute Respiratory Syndrome Coronavirus 2) infection and vulnerable elderly patients at increased risk of complications [13]. At-risk older or quarantined GPs can continue consulting from home, avoiding in-person consultations [14].

By September, 32\% GP consultations were by telehealth: $97 \%$ by phone and used more by women. Video was highest for the 25-44 age group. About 20\% specialists billed MBS telehealth services; of these $16 \%$ were for video, compared with $3 \%$ for GPs [11]. While $16 \%$ is not great for nine years (from 2011), it suggests video services in general practice are likely to increase with time, familiarity and better infrastructure, consistent with international literature [15].

The MBS GP telehealth items have been extended to March 2021, restricted to vulnerable patients with an existing relationship with the GP - defined as an in-person visit in the past 12 months [16]. This restriction has prevented some vulnerable groups from accessing telehealth services [14]. It also worries many private general practices $(60 \%)$ at risk of non-viability as a result of COVID-19 [17]. An Australian private health insurer (Medibank) has extended coverage indefinitely for allied health teleservices [18]. 


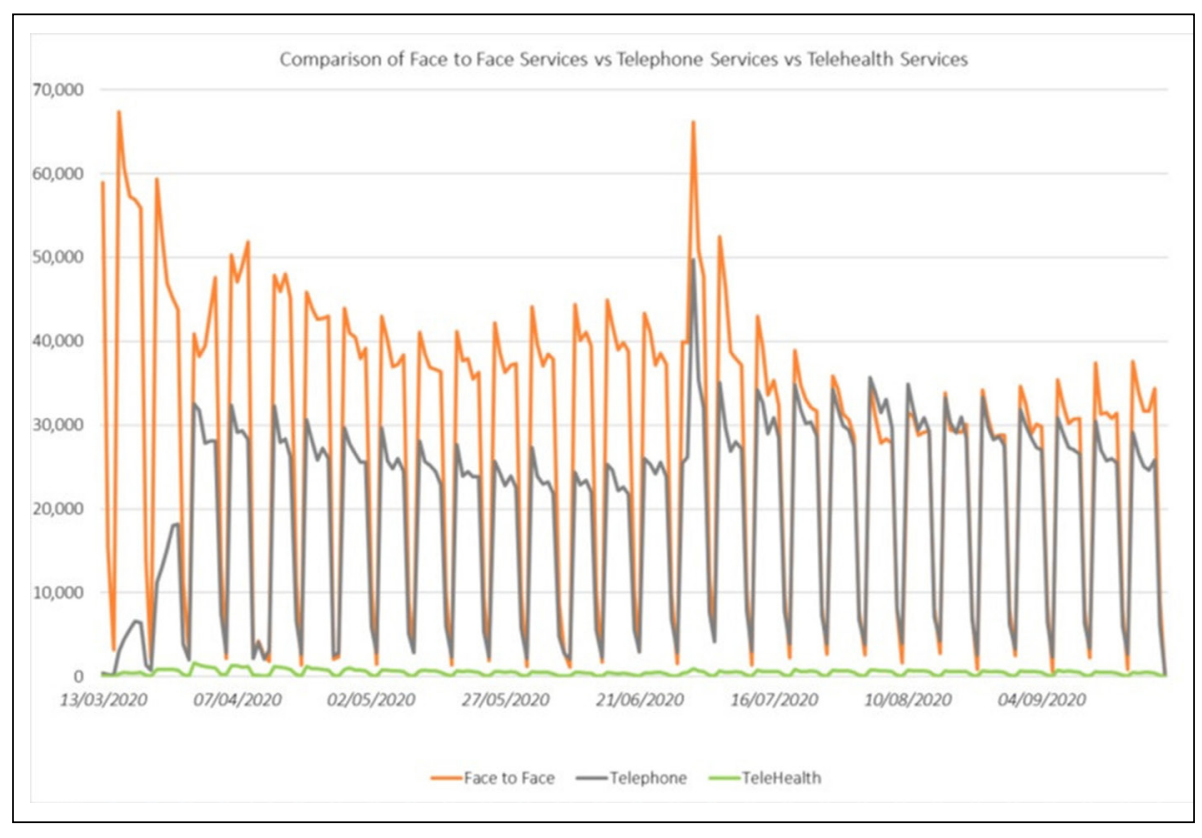

Fig. 1 Daily charting of mode of consultations by GPS in South Eastern Australia. In person consultations declined and phone consultations increased; both after the initial surge. The low levels of telehealth (videoconsultation) remained stable. Source: Pearce C et al. The GP Insights Series no 7.26 0ct 2020 (www.polargp.org.au) [12]

c Implications for primary care informatics Non-standardised development of digital tools: Telemonitoring is increasingly being used for patients at high risk of readmission or who live in residential aged care settings [19]. Current systems are being modified to address COVID-19, an example being the Total Cardiac Care (TCC + ) system which added oximetry to its range of sensor devices [20]. TCC+ is seeking registration as Software as a Medical Device with the Australian Therapeutic Goods Administration. COVIDSafe, a contact tracing app, has been superseded by electronic registration using QR-based technologies at public venues. COVID-19 sped up electronic prescribing, allowing general practices to communicate, using a token or an active script list, with local pharmacies to write and dispense an eScript [21].

Timely access to real-world data (RWD) across the spectrum of care: Population-level data on telehealth are available through Medicare [22]. The POLAR repository contains patient-level RWD extracted from 1000 general practices in
South Eastern Australia [12]. In the first 40 weeks of COVID-19, POLAR data showed marked reduction in GP presentations for childhood infective illnesses (bronchiolitis, gastroenteritis) and antibiotic prescriptions, with concomitant increases in anxiety, depression and eating disorder-related diagnoses. Other data sources showed contemporary decreases in cancer biospecimens and pathology services [23]. A balanced approach for timely cancer diagnosis was recommended and indicates what PCI could focus on $[8,23]$. Mental healthcare support for isolated elderly and young people needs digital enhancement.

Unintended consequences: An Adelaide digital health firm sent patient details and COVID-19 test results to wrong people. Australia's current hybrid method of contact tracing - manual and assisted by spreadsheets and generic customer relationships management solutions - raises questions about safety standards, security and privacy, similar to those posed to the head of UK National Health Service (NHS) Test-and-Trace. d Next steps: What has Australia learned from COVID-19?

Primary care will need support to increase its digital health capacity, including standards for virtual health competencies, training, implementing electronic referrals and $\mathrm{CPOE}$ to enable the delivery of virtual care [24].

\subsection{Canada}

a Healthcare system

COVID-19 has accelerated the Canadian health system to increase virtual care capacity while respecting physical distancing [2]. The challenges are significant for primary care providers (PCP) as they need to deliver regular PC services and also manage COVID-19 screening and contact tracing. There was no national eHealth strategy or system to support the Canadian national COVID-19 response because the separate Province and Territory healthcare delivery systems developed their own strategies and tools including telehealth and virtual care [25], e-referral and intake [26] and a hospital-at-home initiative [27].

\section{b COVID-19 impacts on primary care delivery in Canada}

Canada was challenged by travel restriction delays, insufficient testing, insufficient PPE supply, and difficulties with infection control in long-term care settings [28]. PCPs started working in new settings such as COVID-19 screening and assessment centres. PCPs were encouraged to provide telemedicine and virtual care, with immediate uptake of a virtual-visit-first model. In-person consultations were limited by deferring non-urgent visits. Triaging protocols for virtual visits were developed [29]. Consults were primarily by telephone, but also included email, video conferencing, and telemedicine services (e.g., https://onmd.ca/). Patients were generally satisfied and will continue using virtual care, citing reasons like increased safety, convenience, and accessibility [30].

Each jurisdiction introduced similar regulations such as adapting physician fee schedules, updating practice guidelines, and providing income stabilization [31]. Virtual care billing codes were released in March 2020 [32]; some provinces have since updated 
these codes. Challenges with the new billing codes for virtual visits included delayed payments [15]. There were documented decreases in the use of PC services, likely due to patients self-isolating at home, worries about overstressing the healthcare system and a perceived risk of COVID-19 exposure in healthcare settings [28]. Reductions in contact with PC have reduced routine preventative care, mental health care, and delayed immunizations. Many physicians are concerned about long-term health impacts [33]. Decreased patient visits and delayed payments, coupled with the adoption of new digital workarounds have resulted in financial challenges for many practices [33]. However, despite reduced practice hours, most family physicians have not shut down their offices [34].

\section{c Implications for primary care informatics}

These are positive and negative. While more care could be offered virtually [30], it is recognized this will not eliminate in-person visits for physical examinations and medical procedures. The potential to increase productivity is challenged by PCPs' preoccupation with complexities such as figuring out what is essential versus non-essential care, redirecting patients for tests and procedures, organizing schedules, sanitizing office space, and learning new protocols and technologies [33]. There is no one-size-fits-all solution for informatics support as some tasks are better supported virtually than others. Guiding patients through physical exam tasks such as a hernia diagnosis can be a challenge [35]. In contrast to diagnostic tasks such as cancer screening, mental health care and ongoing management of chronic conditions are areas where virtual care could be particularly impactful [36].

Many areas of Canada had been working on telehealth solutions prior to COVID-19 $[37,38]$. However, with the need to deploy fast and easy virtual care, PCPs were compelled to decide on eHealth tools on their own and learn how to use them [35]. However, the need to develop telehealth systems that meet standards for secure use, communication, and storage of digital health information may be compromised as patients and physicians turn to more user-friendly, but potentially insecure video call platforms instead of tools endorsed by health authorities [36, 39-41].
Virtual care can increase or decrease inequitable access. For Canadians living in rural or remote regions, including First Nations communities, and individuals facing barriers related to mobility, travel costs and time constraints, virtual care has been decidedly beneficial [41]. In contrast, PCPs worry this technology may perpetuate health disparities among seniors, individuals with disabilities, populations with language barriers, and those who cannot afford or use technology [42].

Just as expectations for the continued expansion and use of virtual care are increasing, so does a need for the appropriate health education, clinician training, and peer networks [43].

\section{d Next steps: What has Canada learned from COVID-19?}

COVID-19 like any pandemic or public health emergency, requires integration across sectors of society. A strong primary care-public health interface is critical. Patient and PCP input is important in addressing equity and access for vulnerable populations. Standards for privacy and security of virtual care are necessary. Medical/health education and training is important to ensure a competent workforce. While COVID-19 has highlighted the need for virtual care, effective implementation and adoption is still a long way off $[5,44]$.

\subsection{United Kingdom}

\section{a Healthcare system}

The UK National Health Service (NHS) provides a free service at point of care. Primary care is a registration-based system largely delivered through independent general practices, and consultations have been recorded into computerised medical record (CMR) systems for some years [45]. Each patient is registered with a single general practice. A unique personal identifier, NHS number, links an individual's records across the NHS.

\section{b COVID-19 impacts on primary care delivery in UK}

COVID-19 had a big impact on primary care delivery as there was uncertainty about what constituted an effective infection control policy, with practices largely left to create their own policies [46]. PPE other than face masks, plastic aprons and gloves were initially in short supply [47].

There was initially a drop in the total number of consultations associated with a rise in non-face-to-face with a return to normal rates of consulting within 12 weeks (Fig. 2). There was a move to more non-face-to-face consulting, overwhelmingly by telephone, though the latter included sharing of photographs by email, with only a small rise in e-consultations. In the week that lockdown was announced a record number of patients did not attend their consultations (Fig. 3). In a study of people 65 years and older, it did not appear that the shift to non-face-to-face increased disparities [48].

\section{c Implications for primary care informatics}

The service showed speed and adaptability. A national notice allowing data sharing over the COVID-19 pandemic has allowed innovations in data use including OpenSafely (opensafely.org).

Coding: At the start of the pandemic there were no codes to record COVID-19 infection in primary care CMR systems. CMR system medical directors created temporary codes within days, later replaced with substantive SNOMED clinical terms, though the latter took two iterations [49]. Subsequently these had to be developed into an ontology to enable virologically confirmed, clinically likely, possible and virologically negative cases to be differentiated in routine data [50].

Success of the linkage technology in NHS spine: The NHS spine includes a personal demographics service within the secure NHS network. This lets data about a patient to be linked and shared. This has been particularly important for the largescale testing offered for COVID-19 enabling results to be filed into the relevant patient's primary care record, and early reporting of disparities in those with COVID-19 [50].

Mortality data: Mortality data are also shared via the NHS spine, enabling rapid identification of the peak in mortality associated with the first COVID-19 peak (Fig. 4). This has enabled contemporaneous data to report rates of mortality [51], both those across the population [52] and those with known COVID-19 status [53]. 
Liaw et al.

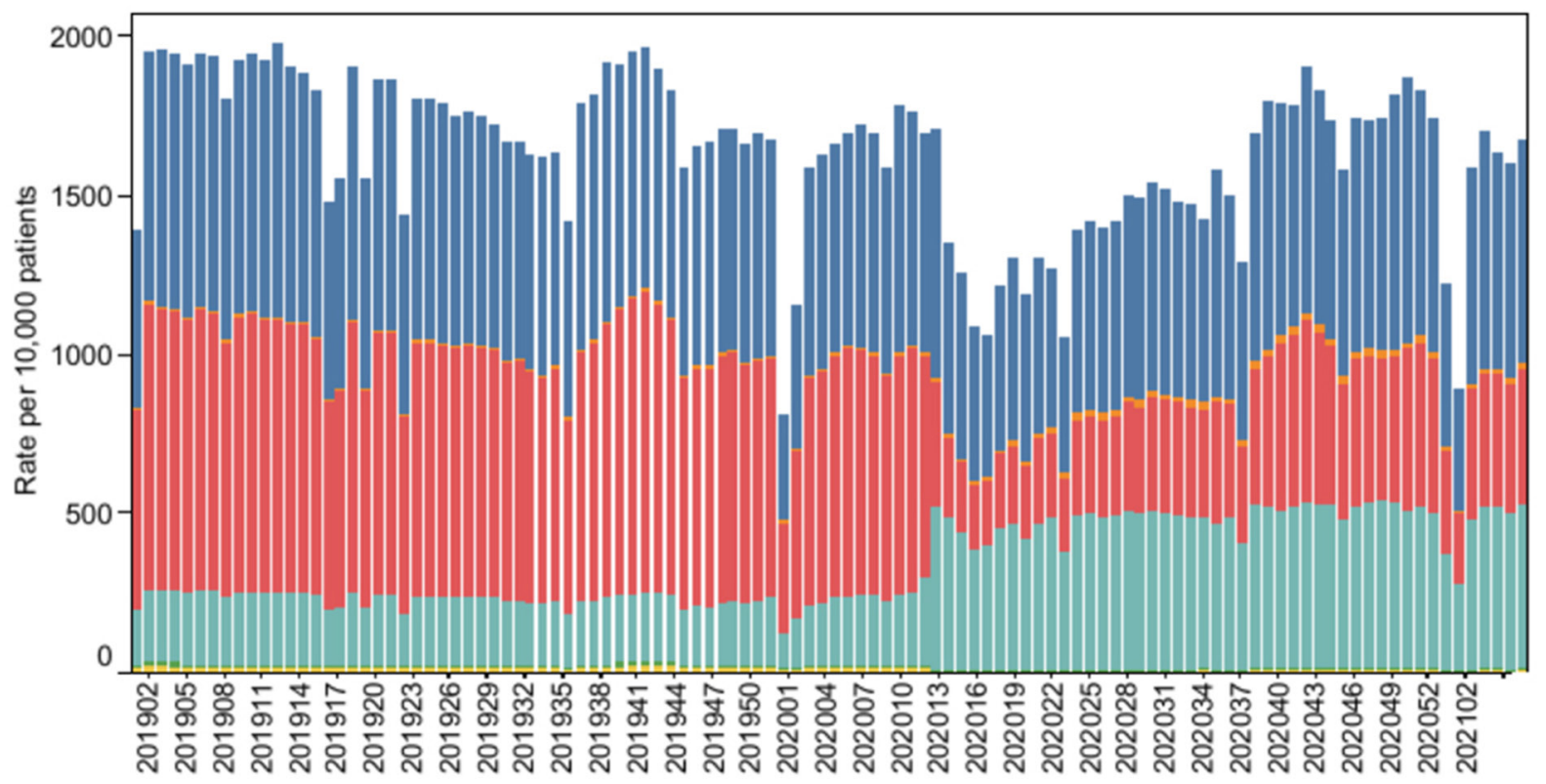

Fig. 2 Weekly consultations by GPs in UK primary care, week 40 of 2018 to week 47 of 2020. In week 12 of 2020, (202012) lockdown was announced and there was a drop in overall consulting. Home visit rates and face to face in surgery declined, linical administration (including text and email) and telephone consulting increased.
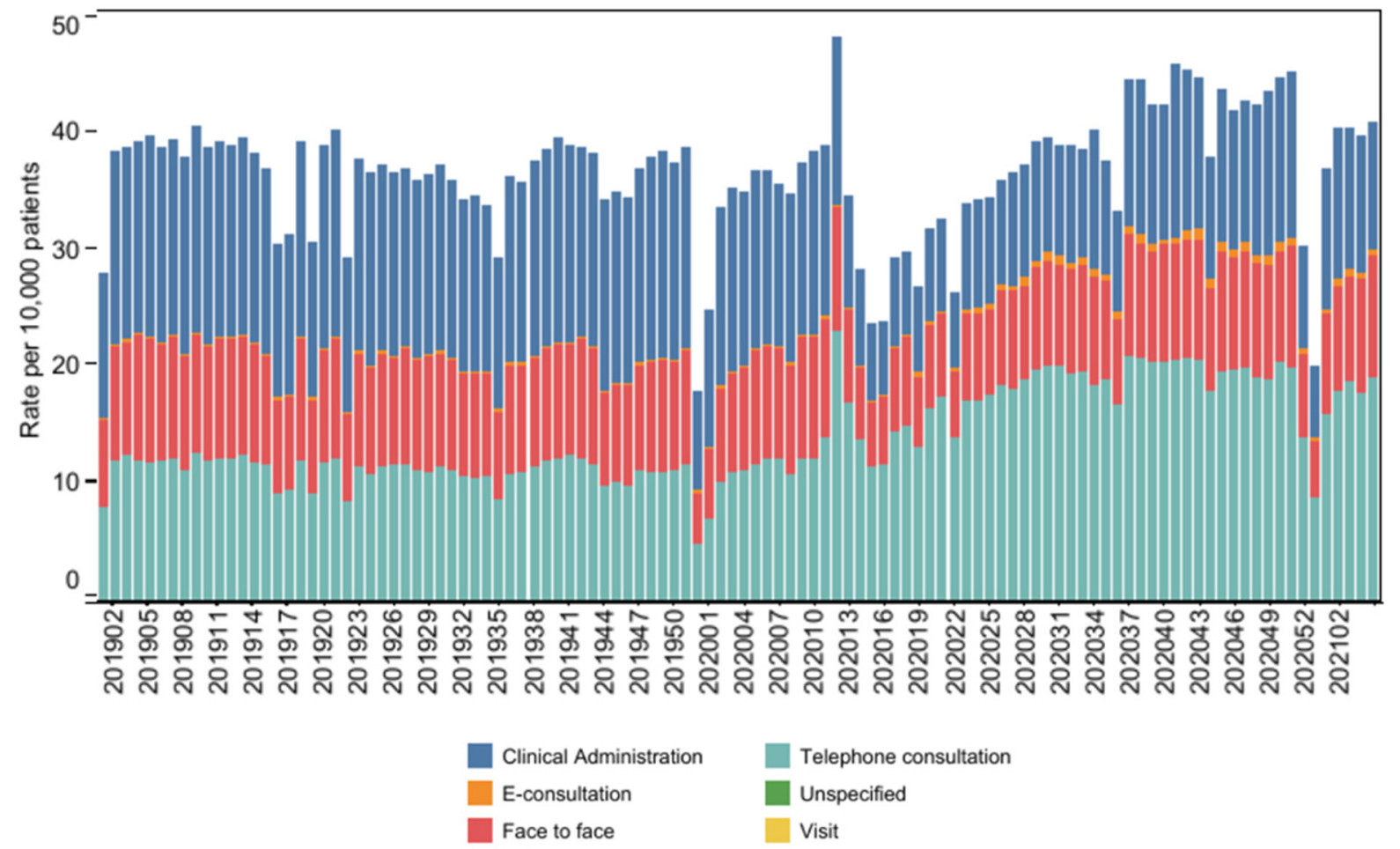

Fig. 3 Rate of failed encounters / did not attend in UK primary care. Week 12 of 2020 was the highest ever recorded for not attending. The rates of non-attendance have not changed with lockdown. 


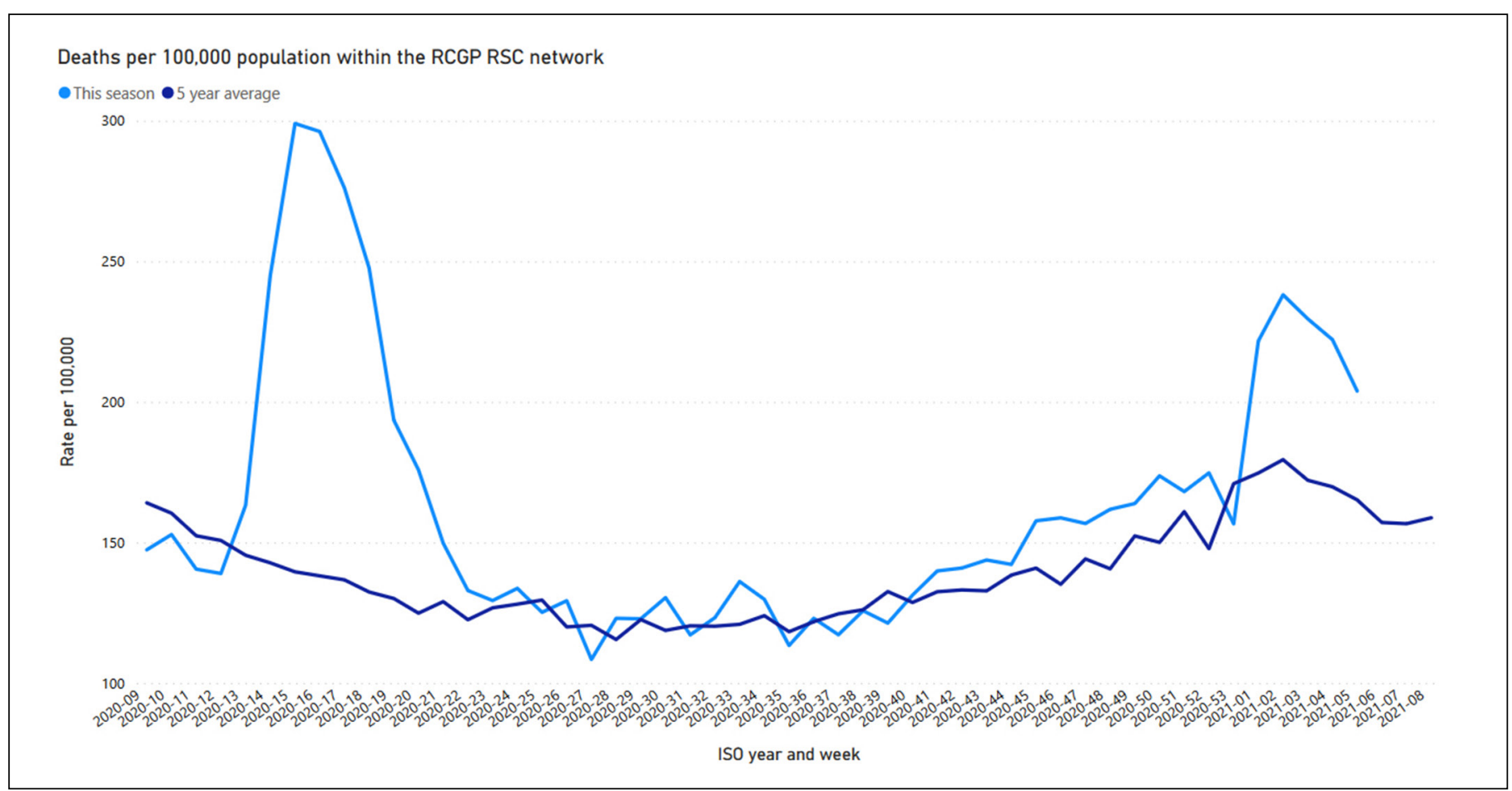

Fig. 4 Mortality in week 49 of 2019 (2019-48), to week 08 of 2021 (2021-08) in people 75 years old and older. The light blue line represents this year, with the peak coinciding with the first wave of COVID-19, the dark blue line the 5 -year mortality average.

d Next Steps: what has UK learned from COVID-19?

The implementation of digital systems accelerated, and there has been a groundswell of willingness of GPs to share data. The Oxford-Royal College of General Practitioners (RCGP) Research and Surveillance Centre (RSC), one of Europe's oldest sentinel systems, trebled its membership over the course of the pandemic [54, 55], and created a range of interactive observatories [56]. This will address the slowness of agencies involved in data linkage to actually share data, even for what have been designated high-priority public health studies. The four nations that make up the UK have separate rules and policies.

\subsection{United States of America}

\section{a Healthcare system}

Telehealth in the USA prior to COVID-19 was largely the province of psychiatrists and psychologists. As lockdowns occurred across the nation, televisits increased exponentially for all clinicians. By March 2020 televisits had already increased by $154 \%$ compared to 2019 [57]. One insurance plan reported a peak in televisits to nearly 18 visits per 1000 enrolees, but with wide geographic variation [58]. Some specialists, e.g., ophthalmologists could not accommodate the need. By Spring many facilities reported that c. $75 \%$ of their ambulatory visits were virtual, including visits for patients with SARS-CoV-2. The US Centers for Medicare and Medicaid Services (CMS) authorized payment for both video and phone based televisits during COVID-19.

b Case study: COVID-19 impacts on primary care delivery at Geisinger Health System in Pennsylvania

COVID-19 cases in central Pennsylvania peaked initially in early May, then decreased until late fall into January 2021 when case numbers exceeded the spring peak. Telehealth enabled Geisinger to continue operations during COVID-19 by decreasing all nonacute visits within primary care sites, temporarily closing small clinics, and tran- sitioning care into larger clinics. Staff were redeployed to primary care offices. The electronic health record (EHR) technical teams completed all configurations, templates and phrases, billing and coding changes, and technical set-up for televisits in a few weeks, similar to experiences elsewhere in USA [59-63]. Use of telehealth increased rapidly to a peak of c. $62 \%$ outpatient encounters (Figure 5). Use depended on technical considerations and whether it was to manage chronic care patients, which was simpler than managing acute problems that required physical examinations.

The few reports regarding implementation of telehealth systems in response to the COVID-19 pandemic come from large centers similar to Geisinger, including the University of California, San Diego [64], the Veterans Administration [59, 60], Boston's Children's Hospital [65], and a few private practices as part of larger academic medical centers [66]. However, it must be noted that the Geisinger experience may not represent the experience across the USA, even for similar sized integrated health systems. 


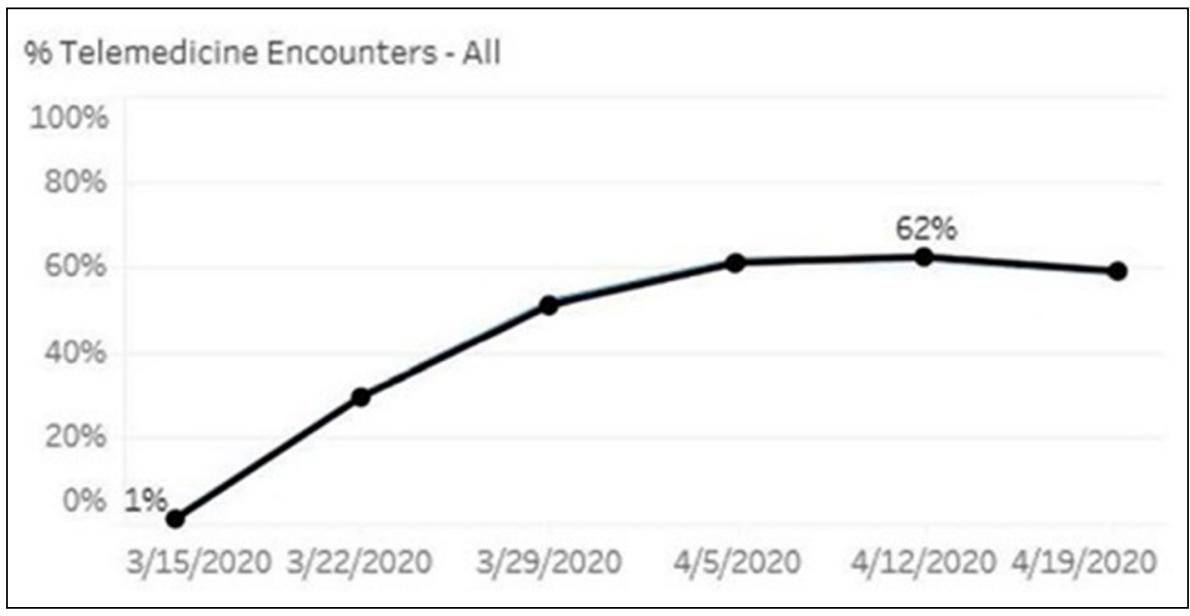

Fig. 5 At its peak in the spring of 2020, telemedicine accounted for $62 \%$ of all outpatient encounters in the Geisinger Health System.

A telemedicine app integrated with the Geisinger EHR system, enabled seamless encounter documentation through templated notes, shortcut phrases for routine documentation, and appropriate phrases to document specifics of televisits per legal and billing requirements. Similar shortcuts were built to communicate test results to patients and work excuses to employers.

Prior to COVID-19, there was no coherent national policy, consistent national reimbursement or incentives to establish the informatics structure to support telehealth. This accelerated with the pressing clinical, social and public health needs from COVID-19. Telehealth practice increased exponentially across the USA [67]. Reservations about telehealth included fear that postponed elective surgeries or unmanaged chronic diseases will result in more care requiring emergency attendances and hospitalizations [68].

\section{c Implications for primary care informatics}

There are informatics, technical, and educational challenges. Training for a new technology is difficult for both providers and patients alike. There is little to no empiric research supporting the efficacy or efficiency of telehealth, or the long-term consequences. The literature is largely rapid-cycle, non-peer reviewed articles. There are concerns about foregoing a regular in-person physical exam beyond simply observing the patient virtually. Further research of these areas is mandatory.

Sufficient bandwidth for both audio and video connections depends on high-speed internet, not available in rural areas or affordable to the poor [69]. "Last mile" connections are problematic, even in urban areas. People may have smartphones but cannot afford Internet access, raising problems of finding Wi-Fi hotspots that also offer privacy and security. Many telehealth applications, especially those tethered to an EHR, require encryption and/or compliance with the Health Insurance Portability and Accountability Act, which may not be compatible with cell phone use. A risk of this inequity is that rural PCPs will be unduly burdened with sicker patients [70].

Setting up televisits was easier for PCPs with mature EHRs, especially those with available telehealth modules. The more agile clinician offices with flexible scheduling succeeded early, especially if they had institutional support. The cessation of elective surgeries, decreased office visits, limited reimbursement for telehealth, and patients not attending routine visits will reduce income and threaten the financial viability of small practices [71]. The CMS expanded telehealth payments for home health agencies [72], but payment for mental health televisits will continue [73]. Some insurance companies have already increased telehealth costs to patients [74].
The COVID-19 pandemic revealed extensive gaps in the ability of the US to respond [75]. Lacking a coherent national COVID-19 response policy, it was left to each state and indeed each hospital system and clinic to develop its own operations [76]. Furthermore, each state licenses its clinicians, and there are no consistent regulations or cross-state agreements for care of patients living close to state borders [77].

\section{d Next Steps: What has USA learned from COVID-19?}

A national not jurisdictional strategy is required to coordinate digital health laws and reimbursement. Foremost among the needs is a national policy requiring cross-state privileges to accommodate both clinicians and patients who live close to a state border and provide or seek services on both sides. Financial and political support for high-speed internet everywhere is critical for sustained success of telehealth. Addressing the challenges and making these regulatory changes will fundamentally alter primary care provision in the United States [78, 79]. Telehealth appears to be firmly established in primary care, and adequate resources made available to sustain it into the post-pandemic era, including managing subsequent pandemics [80].

\subsection{An International Perspective from Some Countries with Lower ICT Developments}

COVID-19 triggered many similar innovations in Indo-Pacific countries with high ICT developments such as China, South Korea and Singapore. A comparison with countries with lower ICT developments, such as India and Pacific Island Countries (PIC), will be more meaningful.

\section{a Pacific Island Countries}

At the least developed end of the ICT development scale [7] are the small and sparsely populated PIC. Primary care is the centre of the health system. The digital health maturity of PIC is generally low, as assessed by considering four essential digital health foundations: ICT infrastructure, essential digital 
health tools (e.g., Unique ID, EHRs and data quality), readiness for information sharing (e.g., interoperability and enterprise architecture) and environment to support adoption (e.g., capacity building, regulations) $[1,81]$. However, telecommunication is fairly well developed to support telemedicine with overseas medical facilities. Most are developing a national digital health strategy using the World Health Organization (WHO) and International Telecommunication Union (ITU) framework [82]. Fortunately, COVID-19 has not been prevalent in the PICT. Nevertheless, local physical and digital arrangements, based on the WHO Early Warning, Alert and Response System [83], are in place to deal with disease outbreak in emergencies such as natural disaster or epidemics as well as support the vaccine strategy. These arrangements will be well and truly tested with the recent COVID-19 outbreak in March 2021 in Papua New Guinea.

\section{b India}

The Indian health system is a federated model with state and central governments having responsibility for various aspects of health. There are significant urban-rural, socioeconomic and gender divides. India aspires to a national digital health system to facilitate the achievement of universal health coverage and United Nations sustainable development goals. State and central governments implemented lockdowns early, introducing targeted COVID-19 clinics and provided PPE and infection control training to PCPs, focusing on early detection, controlling transmission and providing uninterrupted essential primary care services [84].

Telehealth initiatives in India have been struggling to gain momentum for many years [85]. Despite high penetration, mobile phones are not frequently used for health services [81]. Reimbursement for telehealth and telemonitoring services provided by PCPs remain ad hoc. Telemedicine Practice Guidelines for COVID-19 patients were issued on March 25, 2020 [86]. However, the general fragmentation of the digital health system and tools, including between public and private sectors, posed significant feasibility and acceptability challenges. Low mobile phone ownership especially among Indian women raises privacy issues with telehealth. India and many low-and-middle-income-countries (LMICs) are also experiencing decreased use of health services, especially for chronic disease management. A nationwide COVID-19 telephone helpline to complement telehealth services and improve patient and workforce capability was not well received. The WHO-ITU collaboration to directly text the public in LMICs with COVID-19 related information was not adopted or adapted to any significant extent [87].

Data quality and interoperability remain significant challenges to the development of an integrated system to address pandemics into the future. Data collection and management systems are often a hybrid of paper and digital, resulting in inefficiencies and data security issues.

There are many PCI tools readily available to address the data, information and socio-technical aspects of COVID-19. However, despite technical guidance from WHO to support digital health, countries like India have yet to implement policies and regulations at state and national levels. There is an emerging and encouraging shift to a co-creation approach to digital health maturity assessment to guide national digital health strategy development to address COVID-19 and its sequelae on service delivery [1].

\section{Synthesis and Discussion}

Table 1 synthesizes the findings into a set of seven themes, categorized into clinical and public health and informatics and data science issues. Our analysis considered the ITU-ICT rankings of the six countries. The commonalities and variations in the PCI response to COVID-19 emphasises that digital health maturity includes quantitative measures of ICT developments and other sociotechnical determinants, including ensuring data quality, interoperability and readiness for information sharing, and an environment and culture to build capacity and support adoption $[1,81]$. Health and digital literacy of healthcare professionals and citizens are also important, as is previous experience with epidemics such as SARS in the COVID-19 context. Standalone commer- cial telehealth systems need to be monitored for compliance to technical, privacy and security standards.

Countries where healthcare is decentralized to individual provinces, territories, or states present different challenges than in countries where healthcare delivery is centrally funded and delivered. The UK system is centrally funded with autonomy devolved to its four nations. The politics, funding, models of care, and governance of health and social services are important determinants of variations in the COVID-19 response. Cross-country comparisons must also consider culture and contexts. For example, Israel's vaccine delivery model has been heralded as a successful model to emulate [88], but Israel's centralized healthcare delivery approach and relatively small geographic and population size (9M) can make comparisons inaccurate and unfair, even with countries with similar ICT developments [89].

We report our findings in two sections: the first describing how there has been accelerated but patchy progress, the second addressing lessons for the future.

\subsection{Accelerated but Patchy Progress}

Accelerated uptake of telehealth was experienced across all the countries, with important variations in the strategies to protect vulnerable and older people. All countries shared the value inherent in maintaining quality safeguards in health services [90].

Challenges were partly due to regulatory differences between jurisdictions in digital health, information sharing and interoperability [2]. Clinical effectiveness and safety is important, but a successful response to COVID-19 requires a strong primary care-public health interface and standardised information exchange. COVID-19, as with any public health emergency, requires a coordinated national multisectoral response. Despite a strong national primary care and digital health system, the UK has been unable to limit the spread of COVID-19 because of delayed and inconsistent policy decisions on public health approaches based on social distancing and community testing. It may also be due to the balance of public and private providers in Australia and 
Table 1 Themes for PCI response for global pandemic

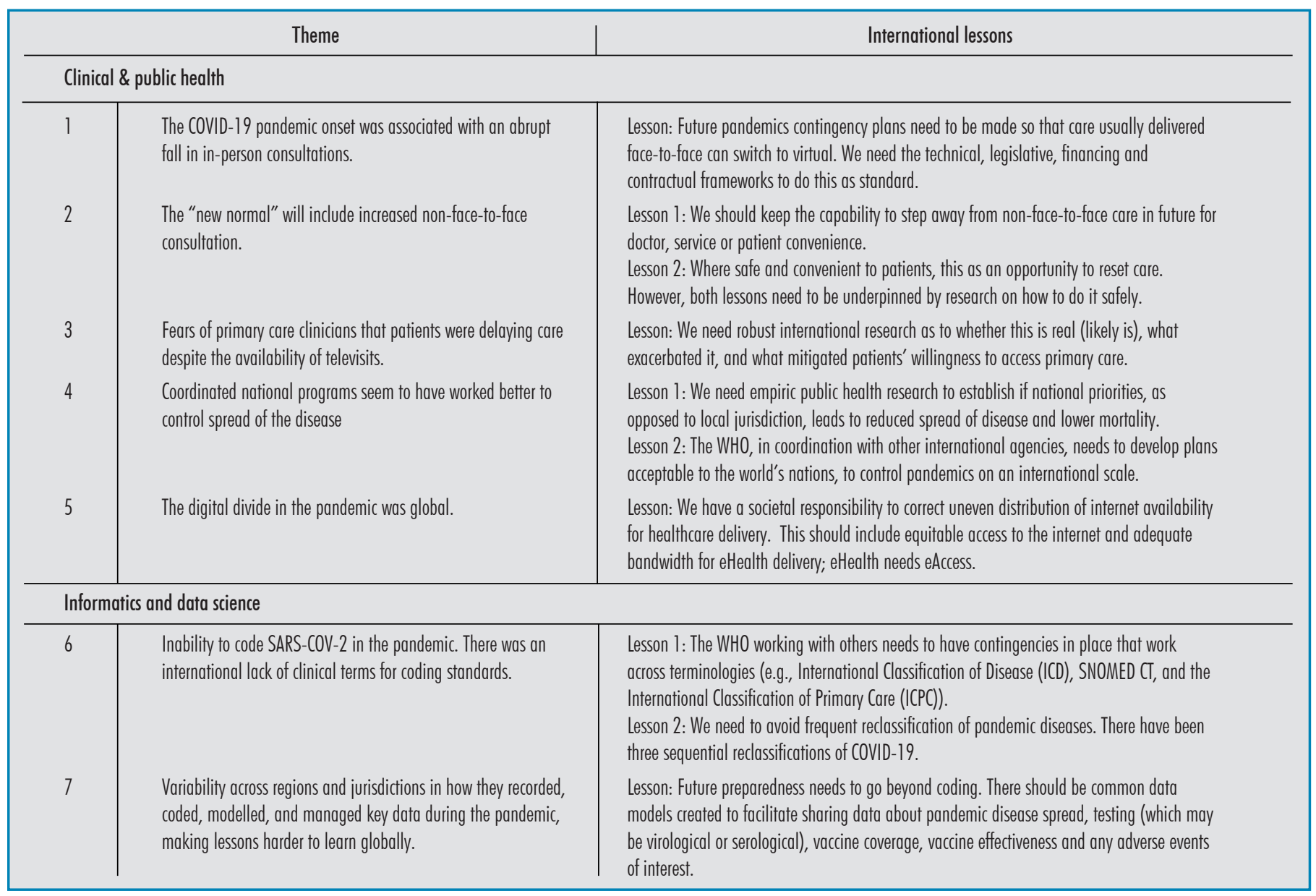

Canada that has enabled its health system to adapt with greater speed and agility than systems that are mainly publicly funded [24] or mainly privatised.

The equity issue and the general lack of evidence for safety and effectiveness of telehealth compared to "in-person" encounters must be addressed. In addition to a rebalancing of spending, lessons from COVID-19 to create a more equitable and effective primary health care system include: provide health services where people are, e.g., expanding the network of community health centres including those in schools and housing complexes; improving inter-racial communication and trust including culturally competent health coaches; strengthen the caregiving workforce for older adults including staff in nursing homes and home-based caregiving systems; and provide equitable or universal health insurance [91].
The primary care data required to successfully identify, manage and monitor pandemics is most advanced in the UK. The use of real-world data from GP systems and record linkage through the NHS spine is a model for other countries, recognising that the political and policy environment needs to be supportive. Adopting international standards such as SNOMED will make primary care data more compliant with FAIR (Findable, Accessible, Interoperable, and Reusable) principles [92].

\subsection{Lessons for the Future}

Timely access to quality data has been a major PCI challenge. Though different health systems have billing and clinical diagnosis provisions for new services during pandemics, provisions for data sharing are lacking.
These obstacles need to be overcome if we are to ever offer truly integrated care services.

Locally-based primary care organisations appear to have rapidly responded by adapting their services to ensure continued equitable access by vulnerable populations to primary care services [42].

COVID-19 has embedded telehealth more firmly in primary care. Virtual care will almost certainly find a stronger place within health service models and is likely to have increased acceptance among both patients and health care providers. However, it is important to recognise that each country is at a different level of digital health maturity and has different health priorities [1,81].

PCI is key to any digital health strategy, and we must maintain the progress made during COVID-19. Telehealth and EHR 
systems underpinned the ability of primary care to be flexible in-pandemic response. However, neither primary care nor PCI can be considered in isolation from the wider health system or health policy context.

\section{Conclusion}

We have conducted case studies in four countries with well-developed ICT systems and examined reported pandemic responses in two less-developed countries. Response was accelerated but progress was patchy. Improved access to good quality data and a standardised approach to information-sharing and development of digital tools to support telehealth and virtual care is foundational. Well-coordinated national response and governance is essential, especially across the primary care and public health sectors. The informatics and digital health responses to the COVID-19 pandemic must not compromise privacy, security, data quality and interoperability standards and other design issues.

\section{Acknowledgements}

Patients and health providers who have allowed data sharing that enabled primary care informatics organisations to contribute to the management of the COVID-19 pandemic.

\section{References}

1. Liaw S-T, Zhou R, Ansari S, Gao J. Digital Health Profile and Maturity Assessment Toolkit: co-creation in the Pacific Islands. J Am Med Inform Assoc 2020 Nov 29:ocaa255.

2. Webster P. Virtual health care in the era of COVID-19. Lancet 2020;395(10231):1180-1.

3. Maldonado JMSdV, Marques AB, Cruz A. Telemedicine: challenges to dissemination in Brazil. Cadernos de Saúde Pública [Internet]. 2016 [cited $2021 \mathrm{Feb}]$; 32(Supp12):e00155615. Available from: https://www.scielo.br/scielo.php?script=sci_arttext\&pid=S0102-311X2016001402005

4. Grönqvist H, Olsson EMG, Johansson B, Held C, Sjöström J, Lindahl Norberg A, et al. Fifteen Challenges in Establishing a Multidisciplinary Research Program on eHealth Research in a University Setting: A Case Study. J Med Internet Res 2017;19(5):e173.

5. Champion C, Kuziemsky C, Affleck E, Alvarez GG. A systems approach for modeling health information complexity. International Journal of
Information Management 2019;49:343-54.

6. Jonnagaddala J, Guo GN, Batongbacal S, Marcelo A, Liaw S-T. Adoption of enterprise architecture for healthcare in AeHIN member countries. BMJ Health Care Inform 2020;27(1):e100136.

7. International Telecommunication Union. Measuring digital development. Facts and figures 2020. Geneva: Internatiomal Telecommunication Union;2020.

8. Duckett $\mathrm{S}$. What should primary care look like after the COVID-19 pandemic? Aust J Prim Health 2020;26(3):207-11.

9. Desborough J, Dykgraaf SH, de Toca L, Davis S, Roberts L, Kelaher C, et al. Australia's national COVID-19 primary care response. Med J Aust 2020;213(3):104-106.e101.

10. Snoswell CL, Caffery LJ, Haydon HM, Thomas $\mathrm{EE}$, Smith AC. Telehealth uptake in general practice as a result of the coronavirus (COVID-19) pandemic. Aust Health Rev 2020;44(5):737-40.

11. Snoswell C, Caffery L, Hobson G, Taylor ML, Haydon HM, Thomas E, et al. Telehealth and coronavirus: Medicare Benefits Schedule (MBS) activity in Australia. Centre for Online Health, The University of Queensland; 2020. Updated May 19, 2020 [cited $2021 \mathrm{Feb} 7$ ]. Available from: https://coh.centre.uq.edu.au/telehealth-and-coronavirus-medicare-benefits-schedule-mbs-activity-australia

12. Pearce C, McLeod A, Gardner K, Supple J, Epstein D, Buttery J. THE GP Insights Series no 7: Primary Care and SARS-CoV-2: The first 40 weeks of the pandemic year. Melbourne: Outcome Health; 26 October 2020

13. Clark M, Brewster D, Jones L, Dhaliwal JS, Teng J. Uncertainty and fear: aged care in a time of COVID-19. MJA Insights+ 2020(44).

14. Baird A. Video communication for GPs and patients. MJA Insight+ 2020(32).

15. Car J, Koh GC-H, Foong PS, Wang CJ. Video consultations in primary and specialist care during the covid-19 pandemic and beyond. BMJ 2020;371:m3945.

16. Medicare Australia. Medicare Benefits Schedule (MBS) Online. Medicare Australia [Internet]; 2020. [cited 2020 Nov 8]. Available from: http:// www.mbsonline.gov.au/internet/mbsonline/publishing.nsf/Content/Home

17. The Royal Australian College of General Practitioners. General Practice: Health of the Nation 2020. East Melbourne, Vic: RACGP;2020.

18. Meidibank Australia. Telehealth support. Look after your health from home with Telehealth. Medibank [Internet]; 2020 [cited 2020 Nov 14]. Available from: https://www.medibank.com. au/health-support/hospital-assist/covid19/telehealth-services/

19. Celler B, Varnfield M, Nepal S, Sparks R, Li J, Jayasena R. Impact of At-Home Telemonitoring on Health Services Expenditure and Hospital Admissions in Patients With Chronic Conditions: Before and After Control Intervention Analysis. JMIR Med Inform 2017;5(3):e29.

20. The University of New South Wales. Total Cardiac Care. UNSW Graduate School of Biomedical Engineering [Internet]; 2020 [cited 2020]. Available from: https://apps.apple.com/au/app/total-cardiac-care/id1437138162

21. Australian Government Department of Health. Electronic prescribing. Australian Government Department of Health [Internet]; 2020. Updated 13 Nov 2020. [cited 2020 Nov 15]. Available from: https://www.health.gov.au/initiatives-and-programs/electronic-prescribing

22. The University of Queensland Centre for Online Health. Telehealth and coronavirus: Medicare Benefits Schedule (MBS) activity in Australia. University of Queensland [Internet]; 2020 [cited 2020 Nov 14]. Available from: https://coh.centre. uq.edu.au/telehealth-and-coronavirus-medicare-benefits-schedule-mbs-activity-australia

23. Helsper CW, Campbell C, Emery J, Neal RD, Li L, Rubin G, et al. Cancer has not gone away: A primary care perspective to support a balanced approach for timely cancer diagnosis during COVID-19. Eur J Cancer Care (Engl) 2020;29(5):e13290.

24. Wright M, Versteeg R, Hall J. General practice's early response to the COVID-19 pandemic. Aust Health Rev 2020;44(5):733-6.

25. Canadian Medical Association-Royal College of Physicians \& Surgeons of Canada-College of Family Physicians of Canada. How to navigate a virtual care visit: patient guide. Canadian Medical Association [Internet]; 2020 [cited 2020 Nov 14]. Available from: https://www.cma.ca/how-navigate-virtual-care-visit-patient-guide

26. Canadian Healthcare Technology. SK deploys COVID-19 e-referral and intake system. Canadian Healthcare Technology [Internet); 2020. [cited 2020 Nov 14]. Available from: https://www. canhealth.com/2020/08/19/sk-deploys-covid-19-ereferral-and-intake-system/

27. Island Health. Hospital at Home - Victoria General Hospital Prototype. Island Health [Internet]; 2020. [cited 2020 Nov 14]. Available from: https://www. islandhealth.ca/our-services/hospital-home-services/hospital-home

28. Huston P, Campbell J, Russell G, Goodyear-Smith F, Phillips Jr RL, van Weel C, et al. COVID-19 and primary care in six countries. BJGP Open 2020;4(4):bjgpopen20X101128.

29. Bhattacharyya O,Agarwal P. Adapting primary care to respond to COVID-19. Can Fam Physician 2020.

30. Canadian Medical Association. What Canadians think about virtual health care. Canadian Medical Association [Internet]; 2020. [cited 2020 Nov 14]. Available from: https://www.cma.ca/sites/default/ files/pdf/virtual-care/cma-virtual-care-public-polljune-2020-e.pdf

31. Canadian Institute for Health Information. Physician billing codes in response to COVID-19. Canadian Institute for Health Information [Internet]; 2020. [cited 2020 Nov 14]. Available from: https://www.cihi.ca/en/physician-billing-codes-inresponse-to-covid-19

32. Ontario Health Insurance Plan. Bulletin Number: 4745: Keeping Health Care Providers informed of payment, policy or program changes. Ministry of Health [Internet]; 2020. Updated $2020 \mathrm{Mar}$ 13. [cited 2021 Feb 7]. Available from: http:// www.health.gov.on.ca/en/pro/programs/ohip/ bulletins/4000/bul4745.aspx

33. Wong S, The Primary and Integrated Health Care Innovations Network. Quick COVID-19 Primary 
Care Survey of Clinicians: Summary of the pan-Canadian survey of frontline primary care clinicians' experience with COVID-19, series 6-11. In: Annals of Family Medicine, COVID-19 Collection. Deepblue: University of Michigan; 2020.

34. Ontario College of Family Physicians. Family Doctors are Open and Here for Care, and More. Ontario College of Family Physicians [Internet]; 2020. [cited 2020 Nov 14]. Available from: https:// www.ontariofamilyphysicians.ca/news-features/ family-medicine-news/ 188-Family-Doctors-areOpen-and-Here-for-Care-and-More

35. GlauserW. Virtual care is here to stay, but major challenges remain. CMAJ 2020;192(30):E868-E869.

36. Deloitte Centre for Health Solutions. COVID-19 Virtual care is here to stay. Deloitte Canada; 2020.

37. Gagnon M-P, Julie D, Fortin J-P. A survey in Alberta and Quebec of the telehealth applications that physicians need. J Telemed Telecare 2007:13(7):352-6.

38. O'Gorman LD, Hogenbirk JC, Warry W. Clinical Telemedicine Utilization in Ontario over the Ontario Telemedicine Network. Telemed J E Health 2015;22(6):473-9.

39. Bhatia RS, Falk W, Jamieson T, Piovesan C, Shaw $\mathrm{J}$. Virtual health care is having its moment. Rules will be needed. Healthydebate [Internet]; 2020. [cited 2020 Nov 14]. Available from: https:// healthydebate.ca/opinions/virtual-health-carerules-covid

40. Appia V. What does the future of telemedicine look like in Ontario after COVID-19? Toronto.com [Internet]; 2020. [cited 2020 Nov 14]. Available from: https://www.toronto.com/news-story/9966360what-does-the-future-of-telemedicine-look-likein-ontario-after-covid-19-/

41. MacLeod M. Virtual health care is 'not the answer for everything,' critics warn. CTV News. Coronavirus updates Web site [Internet]; 2020. [cited 2020 Nov 14]. Available from: https://www.ctvnews.ca/ health/coronavirus/virtual-health-care-is-not-theanswer-for-everything-critics-warn-1.4939283

42. Bhatti S, Commisso E, Rayner J. A Rapid Primary Healthcare Response to COVID-19: An Equity-Based and Systems-Thinking Approach to Care Ensuring that No One Is Left Behind. Healthc Q 2020;23(3):29-33.

43. Bhyat R. Canada's 'new normal' must include virtual care. Healthydebate [Internet]; 2020. [cited 2020 Nov 14]. Available from: https://healthydebate.ca/ opinions/new-normal-include-virtual-care

44. Mosnaim GS, Stempel H, Van Sickle D, Stempel DA. The Adoption and Implementation of Digital Health Care in the Post-COVID-19 Era. J Allergy Clin Immunol Pract 2020;8(8):2484-6.

45. Schade CP, Sullivan FM, de Lusignan S, Madeley J. e-Prescribing, Efficiency, Quality: Lessons from the Computerization of UK Family Practice. J Am Med Inform Assoc 2006;13(5):470-5.

46. de Lusignan S, Carlyon T, Lalvani A. Removing the handle of the Broad Street pump: measures to slow the spread of covid-19 in primary care teams. BMJ 2020;369:m1841.

47. Dyer C. Covid-19: Doctors make bid for public inquiry into lack of PPE for frontline workers. BMJ 2020;369:m1905.

48. Joy M, McGagh D, Jones N, et al. Reorganisation of primary care for older adults during COVID-19: a cross-sectional database study in the UK. Br J Gen Pract 2020;70(697):e540.

49. de Lusignan S, Williams J. To monitor the COVID-19 pandemic we need better quality primary care data. BJGP Open 2020;4(2):bjgpopen20X101070.

50. de Lusignan S, Dorward J, Correa A, et al. Risk factors for SARS-CoV-2 among patients in the Oxford Royal College of General Practitioners Research and Surveillance Centre primary care network: a cross-sectional study. Lancet Infect Dis 2020;20(9):1034-42.

51. Joy M, Hobbs FDR, McGagh D, Akinyemi O, de Lusignan S. Excess mortality from COVID-19 in an English sentinel network population. Lancet Infect Dis 2020 Aug 4;S1473-3099(20)30632-0.

52. de Lusignan S, Joy M, Oke J, McGagh D, Nicholson B, Sheppard J et al. Disparities in the excess risk of mortality in the first wave of COVID-19: Cross sectional study of the English sentinel network. J Infect 2020;81(5):785-92.

53. Joy M, Hobbs FDR, Bernal JL, Sherlock J, Amirthalingam $\mathrm{G}, \mathrm{McGagh} \mathrm{D}$ et al. Excess mortality in the first COVID pandemic peak: cross-sectional analyses of the impact of age, sex, ethnicity, household size, and long-term conditions in people of known SARS-Cov-2 status in England. Br J Gen Pract 2020:bjgp20X713393.

54. de Lusignan S, Lopez Bernal J, Zambon M, Akinyemi $\mathrm{O}$, Amirthalingam $\mathrm{G}$, Andrews $\mathrm{N}$, et al. Emergence of a Novel Coronavirus (COVID-19): Protocol for Extending Surveillance Used by the Royal College of General Practitioners Research and Surveillance Centre and Public Health England. JMIR Public Health Surveill 2020;6(2):e18606.

55. de Lusignan S, Bernal J, Byford R, Amirthalingam $\mathrm{G}$. Seasonal influenza surveillance and vaccine effectiveness at a time of co-circulating COVID-19: Oxford-Royal College of General Practitioners (RCGP) Research and Surveillance Centre (RSC) and Public Health England (PHE) protocol for winter 2020/21 (Preprint). 2020.

56. University of Oxford CIHORG. RCGP RSC COVID-19 Observatory and Coding Guidelines. University of Oxford [Internet]; 2021. [cited 2021 Feb 13]. Available from: https://orchid.phc.ox.ac. uk/index.php/cov-19

57. Koonin LM, Hoots B, Tsang CA, Leroy Z, Farris $\mathrm{K}$, Jolly T, et al. Trends in the Use of Telehealth During the Emergence of the COVID-19 Pandemic - United States, January-March 2020. MMWR Morb Mortal Wkly Rep 2020 Oct 30;69(43):1595-9.

58. Patel S, Mehrotra A, Huskamp H, Uscher-Pines L, Ganguli I, Barnett ML. Trends in outpatient care delivery and telemedicine during the COVID-19 pandemic in the US. JAMA Intern Med $2021 \mathrm{Mar}$ 1;181(3):388-91.

59. Reddy A, Gunnink E, Deeds SA, Hagan SL, Heyworth L, Mattras TF, et al. A rapid mobilization of 'virtual' primary care services in response to COVID-19 at Veterans Health Administration. Healthc (Amst) 2020;8(4):100464-100464.

60. Spelman JF, Brienza R, Walsh RF, Drost P, Schwartz AR, Kravetz JD, et al. A Model for Rapid Transition to Virtual Care, VA Connecticut Primary Care Response to COVID-19. J Gen Intern Med 2020;35(10):3073-6.
61. Sinha S, Kern LM, Gingras LF, Reshetnyak E, Tung J, Pelzman F, et al. Implementation of Video Visits During COVID-19: Lessons Learned From a Primary Care Practice in New York City. Front Public Health 2020;8:514-22.

62. Srinivasan M, Asch S, Vilendrer S, Crandall Thomas S, Bajra R, Barman L, et al. Qualitative Assessment of Rapid System Transformation to Primary Care Video Visits at an Academic Medical Center. Ann Intern Med 2020;173(7):527-35.

63. Smith WR, Atala AJ, Terlecki RP, Kelly EE, Matthews CA. Implementation Guide for Rapid Integration of an Outpatient Telemedicine Program During the COVID-19 Pandemic. J Am Coll Surg 2020;231(2): 216-222.e2

64. Reeves JJ, Hollandsworth HM, Torriani FJ, Taplitz R, Abeles S, Tai-Seale M, et al. Rapid Response to COVID-19: Health Informatics Support for Outbreak Management in an Academic Health System. J Am Med Inform Assoc 2020 Jun 1;27(6):853-9.

65. Hron JD, Parsons CR, Williams LA, Harper MB, Bourgeois FC. Rapid Implementation of an Inpatient Telehealth Program during the COVID-19 Pandemic. Appl Clin Inform 2020;11(3):452-9.

66. Sinha S, Kern LM, Gingras LF, Tung J, Pelzman F, et al. Implementation of Video Visits During COVID-19: Lessons Learned From a Primary Care Practice in New York City. Front Public Health 2020;8:514.

67. Ranney ML, Griffeth V, Jha AK. Critical Supply Shortages - The Need for Ventilators and Personal Protective Equipment during the Covid-19 Pandemic. N Engl J Med 2020;382(18):e41.

68. Brodwin E. With covid-19 delaying routine care chronic disease startups brace for a slew of complications. Health Tech 2020 Apr 14 [cited 2020 Nov 14]. Available from: https://www.statnews. com/2020/04/14/with-covid-19-delaying-routinecare-chronic-disease-startups-brace-for-a-slew-ofcomplications/

69. Jaffe DH, Lee L, Huynh S, Haskell TP. Health Inequalities in the Use of Telehealth in the United States in the Lens of COVID-19. Popul Health Manag 2020;23(5):368-77.

70. Summers-Gabr NM. Rural-urban mental health disparities in the United States during COVID-19. Psychol Trauma 2020;12(S1):S222-S224.

71. Basu S, Phillips RS, Phillips R, Peterson LE, Landon BE. Primary Care Practice Finances In The United States Amid The COVID-19 Pandemic. Health Aff (Millwood) 2020;39(9):1605-14.

72. United States Centers for Medicare and Medicaid Services (CMS). Home health agencies: CMS flexibilities to fight Covid-19. Washington DC: Centers for Medicare and Medicaid Services; 2020.

73. US Centers for Medicare \& Medicaid Services. Medicare telemedicine health care provider fact sheet [Internet] 2020. Updated 2020 March 17 [cited $2021 \mathrm{Feb} 6]$. Available from: https://www. cms.gov/newsroom/fact-sheets/medicare-telemedicine-health-care-provider-fact-sheet

74. Robbins R, Brodwin E. As insurers move this week to stop waiving telehealth copays, patients may have to pay more for virtual care. STAT+. Health Tech Web site [Internet]; 2020. [cited 2020 Nov 14]. Available from: https://www.statnews. com/2020/09/29/united-healthcare-anthem-telemedicine-coverage-insurers/ 
75. Subbian V, Solomonides A, Clarkson M, Rahimzadeh VN, Petersen C, Schreiber R, et al. Ethics and informatics in the age of COVID-19: challenges and recommendations for public health organization and public policy. J Am Med Inform Med Assoc 2021;28(1):184-9.

76. Chen C. America Doesn't Have a Coherent Strategy for Asymptomatic Testing. It Needs One. In: ProPublica, Vol 20212020

77. Katzow MW, Steinway C, Jan S. Telemedicine and Health Disparities During COVID-19. Pediatrics 2020;146(2):e20201586.

78. Krist AH, DeVoe JE, Cheng A, Ehrlich T, Jones SM. Redesigning Primary Care to Address the COVID-19 Pandemic in the Midst of the Pandemic. Ann Fam Med 2020;18(4):349-54.

79. Lin S, Sattler A, Smith M. Retooling Primary Care in the COVID-19 Era. Mayo Clinic Proceedings 2020;95(9):1831-4.

80. Mehrotra A, Bhatia RS, Snoswell CL. Paying for Telemedicine After the Pandemic. JAMA 2021;325(5):431-2.

81. Godinho MA, Jonnagaddala J, Gudi N, Islam R, Narasimhan P, Liaw S-T. mHealth for Integrated People-Centred Health Services in the Western Pacific: A Systematic Review. Int J Med Inform 2020;142:104259.
82. World Health Organisation \& International Telecommunication Union. WHO-ITU: National eHealth Strategy Toolkit. Geneva: WHO \& ITU; 2012.

83. World Health Organisation. Early Warning, Alert and Response System (EWARS). WHO [Internet], 2020. [cited 2020 Nov 14]. Available from: https:// www.who.int/emergencies/surveillance/earlywarning-alert-and-response-system-ewars

84. Venkata-Subramani M, Roman J. The Coronavirus Response in India - World's Largest Lockdown. Am J Med Sci 2020:S0002-9629(0020)30351-30357.

85. Agarwal N, Jain P, Pathak R, Gupta R. Telemedicine in India: A tool for transforming health care in the era of COVID-19 pandemic. J Educ Health Promot 2020;9:190-190.

86. Dinakaran D, Basavarajappa C, Manjunatha N, Kumar CN, Math SB. Telemedicine Practice Guidelines and Telepsychiatry Operational Guidelines, India-A Commentary. Indian J Psychol Med 2020;42(5_suppl):1S-3S.

87. World Health Organisation. ITU-WHO Joint Statement: Unleashing information technology to defeat COVID-19. ITU-WHO [Internet]; 2020. [cited 2020 Nov 14]. Available from: https://www. who.int/news/item/20-04-2020-itu-who-jointstatement-unleashing-information-technology-todefeat-covid-19
88. Friedman U. One Country Has Jumped Ahead on Vaccinations Israel has vaccinated six times more of its population than the United States. Can others learn from its success? The Atlantic 23 Jan, 2021.

89. Waitzberg R, Davidovitch N. Israel's vaccination rollout: short term success, but questions for the long run. theBMJopinion 2021 Feb 5.

90. Fisk M, Livingstone A, Pit SW. Telehealth in the Context of COVID-19: Changing Perspectives in Australia, the United Kingdom, and the United States. J Med Internet Res 2020;22(6):e19264.

91. Butler SM. Four COVID-19 Lessons for Achieving Health Equity. JAMA Health Forum 2020;1(11):e201370-e201370.

92. Wilkinson MD, Dumontier M, Aalbersberg IJ, Appleton G, Axton M, Baak A et al. The FAIR Guiding Principles for scientific data management and stewardship. Sci Data 2016;3:160018.

\section{Correspondence to:}

Emeritus Professor Siaw-Teng Liaw WHO Collaborating Centre on eHealth

School of Population Health

UNSW Sydney

Australia

E-mail: siaw@unsw.edu.au 